\title{
Analysis on the Coupled System of Vibratory Roller Vibration Wheel and Soil
}

\author{
Jing Wang, Wei Zhang, Hongyu Xu
}

Civil Engineering School,Henan University of Science and Technology, Luoyang 471023,China 1327251833@qq.com

Key Words: vibratory roller; wheel vibration; amplitude;

Abstract: In this paper, the intelligent vibration road roller system is simplified to three degrees of freedom dynamic system, the differences between the dynamics model with past is that we not only considering two degrees (vibration wheel, the soil or frame, wheels), But at the same time considering vibratory wheel, frame and the soil under the interaction of three degree of freedom vibration. In this text, Vibratory roller vibration system is mainly studied in the vertical direction vibration, by solving equations, obtaining the expression of the wheel vibration amplitude, the relationship between wheel vibration amplitude and the various soil parameters are studied by using numerical analysis method, the influence of various parameters on the amplitude is discussed. The results show that the parameters of soil have different degrees of influence on amplitude. Among them, the soil stiffness has the most effection on the amplitude the results can provide the reference data for vibration system design and the real-time monitoring, control of the vibration response.

\section{Introduction}

From the early 1940s, the birth of the first self-propelled roller to the present, the vibratory roller has great changes in form and function, vibratory roller entered a new period of development.Intelligent vibratory roller becomes the new trend of development[1]. The amplitude of vibratory roller is the amount of roller wheel to move up and down, for compaction depth requirements of soil, the more amplitude of the roller, the more the quality of the material in vibration, increasing compaction influence depth or thickness [2-5]. consider only two degrees of freedom is the case in the past, In this paper, the intelligent vibration road roller system is simplified to three degrees of freedom dynamic system, but at the same time considering vibratory wheel, frame and the soil. Vibratory roller vibration system is mainly studied in the vertical direction vibration, by solving equations, obtaining the expression of the wheel vibration amplitude, the relationship between wheel vibration amplitude and the various soil parameters are studied by using numerical analysis method, the influence of various parameters on the amplitude is discussed. To provide the reference for the realization of intelligent control of roller design.

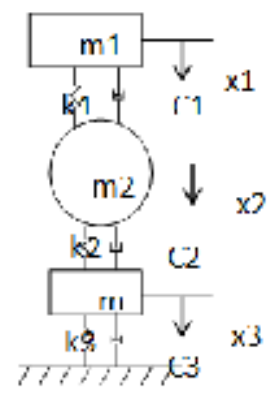

Fig. 1 the system dynamics model diagram 


\section{Formulation and solution of the coupled system of vibratory roller-vibration wheel and soil}

Roller vibration system is mainly studied in the vertical direction vibration, roller-vibratory wheel-soil the system dynamics model diagram is shown in figure 1.

Vibration wheel and eccentric mass and main structure along the longitudinal axis symmetric, so system vibration model can be simplified as plane dynamic problems; The vibration of the vibrating road roller wheel, the quality of the frame is simplified to concentrated mass respectively, soil compaction, vibration wheel and frame together as a quality - spring - damper system, ignore the quality of spring and damping; Assuming that the soil is a certain stiffness of the elastomer, the roller's rigidity and damping and soil stiffness and damping into consideration; Only consider the degrees of freedom vertical direction vibration of the vibration wheel, and ignore the rotational degree of freedom. vibration wheel of Vibratory roller keep contact with the ground at any momment.

$m_{1}, m_{2}, m_{3}$ - the quality of the roller on the frame, the quality of the vibration and the soil;

$c_{1}, \quad c_{2}, \quad c_{3}$-On the frame of vertical damping, vertical wheel and soil vertical damping;

$k_{1}, k_{2}, k_{3}$-On the frame of vertical stiffness, Vibration wheel and soil vertical stiffness.

Vibration system dynamics model is shown in type (1).

$\left\{\begin{array}{l}m_{3}+\left(c_{2}+c_{3}\right) d-c_{2}+\left(k_{2}+k_{3}\right) x_{3}-k_{2} x_{2}=0 \\ m_{2}+\left(c_{1}+c_{2}\right) \&-c_{2} d-c_{1} x+\left(k_{1}+k_{2}\right) x_{2}-k_{2} x_{3}-k_{1} x_{1}=-F_{0} \sin w t \\ m_{1}+c_{1} d-c_{1} \&+k_{1} x_{1}-k_{1} x_{2}=0\end{array}\right.$

Among: $[k]=\left[\begin{array}{l}k_{2}+k_{3},-k_{2}, 0 \\ -k_{2}, k_{1}+k_{2},-k_{1} \\ 0,-k_{1} k_{1}\end{array}\right] \quad[c]=\left[\begin{array}{l}c_{2}+c_{3},-c_{2}, 0 \\ -c_{2}, c_{1}+c_{2},-c_{1} \\ 0,-c_{1}, c_{1}\end{array}\right] \quad[x]=\left[\begin{array}{l}x_{3} \\ x_{2} \\ x_{1}\end{array}\right]$

$[F]=\left[\begin{array}{l}0 \\ -F_{0} \sin w t \\ 0\end{array}\right] \quad[m]=\left[\begin{array}{c}m_{3}, 0,0 \\ 0, m_{2}, 0 \\ 0,0, m_{1}\end{array}\right]$

Because the model is a linear time invariant system, incentive is the resonant force, so the steady state response is also resonant displacement. For solving the dynamic equation (1), Use the plural vector representation, $\mathrm{F}_{0} e^{i w t}$ is vibration force, $\quad x_{1}=A_{1} e^{i\left(w t-\alpha_{1}\right)}, \quad x_{2}=A_{2} e^{i\left(w t-\alpha_{2}\right)}, \quad x_{3}=A_{3} e^{i\left(w t-\alpha_{3}\right)}$

$A_{1}, A_{2}, A_{3}$ - the amplitude of instantaneous displacement $x_{1}, x_{2}, x_{3}$;

$\alpha_{1}, \alpha_{2}, \alpha_{3}$ - phase Angle of instantaneous displacement $x_{1}, x_{2}, x_{3}$ behind the exciting force $\mathrm{F}$

Take $=\mathrm{iw} x_{1},=-w^{2} x_{1} ;=\mathrm{iw} x_{2}, \quad=-w^{2} x_{2} ; \quad$ \& $=\mathrm{iw} x_{3}, \quad=-w^{2} x_{3}$ to type (1):

$\left[-m_{3} w^{2}+i w\left(c_{2}+c_{3}\right)+k_{2}+k_{3}\right] x_{3}+\left(-i w c_{2}-k_{2}\right) x_{2}=0$

$\left.\left(-i w c_{2}-k_{2}\right) x_{3}+\left[-m_{2} w^{2}+i w\left(c_{1}+c_{2}\right)+k_{1}+k_{2}\right)\right] x_{2}+\left(-i w c_{1}-k_{1}\right) x_{1}=-\mathrm{F}_{0} e^{i w t}$

$\left(-i w c_{1}-k_{1}\right) x_{2}+\left(-m_{1} w^{2}+i w c_{1}+k_{1}\right) x_{1}=0$

Among, $\mathrm{M}=\left[-m_{3} w^{2}+i w\left(c_{2}+c_{3}\right)+k_{2}+k_{3}\right], \quad \mathrm{N}=\left(-i w c_{2}-k_{2}\right), \quad \mathrm{P}=\left(-i w c_{2}-k_{2}\right)$

$\left.\mathrm{Q}=\left[-m_{2} w^{2}+i w\left(c_{1}+c_{2}\right)+k_{1}+k_{2}\right)\right], \quad \mathrm{R}=\left(-i w c_{1}-k_{1}\right), \quad \mathrm{Z}=\left(-i w c_{1}-k_{1}\right)$,

$\mathrm{G}=\left(-m_{1} w^{2}+i w c_{1}+k_{1}\right)$

$x_{2}=A_{2} e^{i\left(w t-\alpha_{2}\right)}=\mathrm{F}_{0} e^{i w t} \mathrm{MGQ} /\left(\mathrm{PNGQ}-\mathrm{Q}^{2} \mathrm{MG}+\mathrm{ZRMQ}\right)$

$A_{2} e^{-i \alpha_{2}}=F_{0} \quad \mathrm{MGQ} /\left(\mathrm{PNGQ}-\mathrm{Q}^{2} \mathrm{MG}+\mathrm{ZRMQ}\right)=F_{0}(a+b i) /(c+d i)$

Among: $F_{0}=w^{2} M e, A_{2}=F_{0} \sqrt{\left(a^{2}+b^{2}\right) /\left(c^{2}+d^{2}\right)}$ 
This shows the vibration amplitude of dynamics model is the function of vibration parameters in the vibration system, to study the influence of dynamic model input parameters on the vibration response, on the basis of reference literatures and the performance of the vibrating road roller, The system related to the input parameter generation into the system response function, obtain corresponding relation curve through numerical calculation, discuss the system main input parameters effect on the output parameters of the system.

\section{Numerical calculation and analysis}

By the response type(2) about the dynamic model of the frame- vibratory wheel- soil, we know, in the system of vibration compaction, output parameters and input parameters of the dynamic model is a nonlinear relationship.By setting a single change of input parameters, and the rest of the input parameters as constant value, through numerical analysis the influence law of system stiffness, damping and vibration with the soil quality of vibration, the vibration frequency or exciting force on the system response, get on the frame -vibration wheel - soil vibration compaction system input parameters and the relationship between the wheel vibration amplitude.

According to the common vibrating road roller design data and the related literature to determine the parameters: $k_{s}=1.5 \times 10^{7} \mathrm{~N} / \mathrm{m}, c_{S}=7.2 \times 10^{4} \mathrm{Ns} / \mathrm{m}, m_{1}=1500 \mathrm{~kg}, m_{2}=3000 \mathrm{~kg}, m_{3}=1800 \mathrm{~kg}$, $w=1500 \mathrm{r} / \mathrm{min}, \quad M e=5 \mathrm{kgm} ;$ And take $c_{1}=c / 6, c_{2}=c / 2, c_{3}=c / 3, k_{1}=k / 6, k_{2}=k / 2$, $k_{3}=k / 3$

Take $m_{1}, m_{2}, m_{3}, k_{1}, k_{2}, k_{3}, c_{1}, c_{2}, w$ to type (2), obtain expression of vibratory roller wheel vibration amplitude about $c_{3}$, To study wheel vibration amplitude changes, When the soil damping change from $0.1 \mathrm{c}(1200 \mathrm{~ns} / \mathrm{m})$ to c $(12000 \mathrm{~ns} / \mathrm{m}), \mathrm{c}(12000 \mathrm{~ns} / \mathrm{m})$ to $10 \mathrm{c}(120000 \mathrm{~ns} / \mathrm{m})$. According to the above numerical results, amplitude A on soil parameters $\mathrm{k}, \mathrm{c}, \mathrm{m}$ are obtained by Matlab software and vibration wheel vibration frequency of a series of functional relation curve as shown in the figure below( $\mathrm{K}$ is the distribution stiffness of soil ,c is the distribution of soil damping coefficient, $\mathrm{M}$ is the study of soil quality, $\mathrm{W}$ is the vibration wheel vibration frequency).

In the figure 2, amplitude about damping reduce from $1.678 \mathrm{~mm}$ to $1.678 \mathrm{~mm}$ between $0.1 \mathrm{c}$ (1200 $\mathrm{ns} / \mathrm{m})$ and c $(12000 \mathrm{~ns} / \mathrm{m})$, Figure 3 reflects the amplitude about damping reduce from $1.662 \mathrm{~mm}$ to $1.33 \mathrm{~mm}$ between c $(12000 \mathrm{~ns} / \mathrm{m})$ and $10 \mathrm{c}(120000 \mathrm{~ns} / \mathrm{m})$.

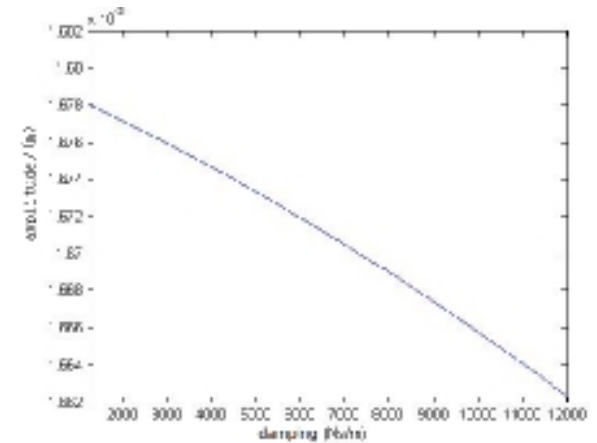

Fig.2 function relation curve of damping(0.1c-c) $\mathrm{n} / \mathrm{m})$, increase from $0.781 \mathrm{~mm}$ to 0.781 .

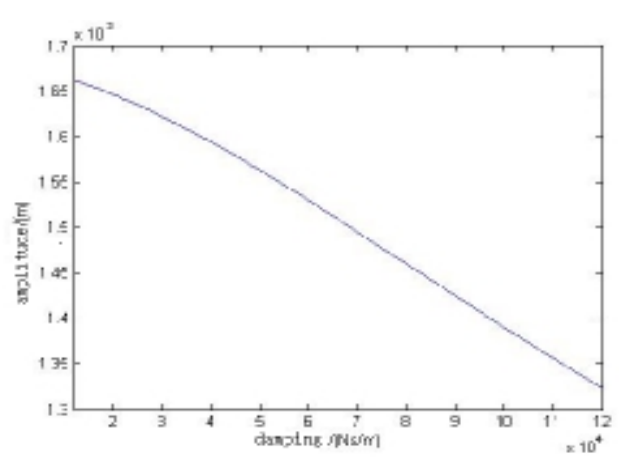

Fig.3 function relation curve of damping(c-10c) about amplitude curve between $0.1 \mathrm{k}(250000 \mathrm{n} / \mathrm{m})$ and $\mathrm{k}(2500000$ 


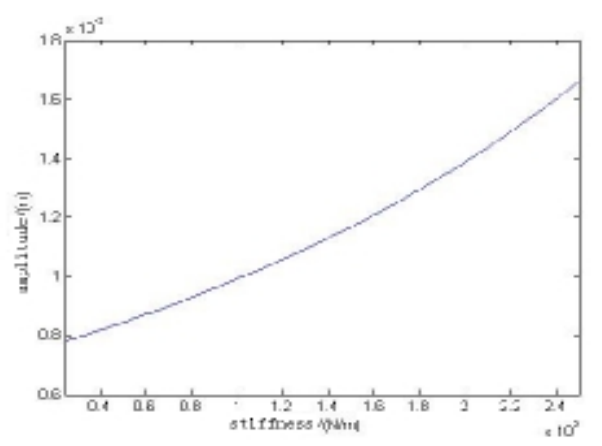

Fig.4 function relation curve of stiffness $(0.1 \mathrm{k}-\mathrm{k})$

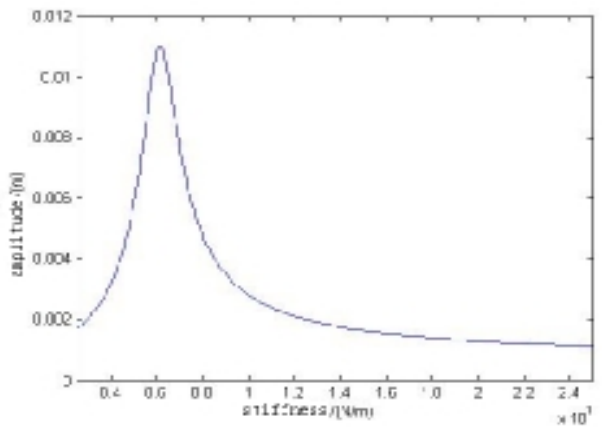

Fig.5 function relation curve of stiffness $(\mathrm{k}-10 \mathrm{k})$ about amplitude

Figure 6 is the curve of ampltude about quality between $0.1 \mathrm{~m}(180 \mathrm{~kg})$ and $\mathrm{m}(1800 \mathrm{~kg})$, reduce from $2.52 \mathrm{~mm}$ to $1.662 \mathrm{~mm}$.Figure 7 is the amplitude $(1800 \mathrm{~kg})$ about quality from $1 \mathrm{~m}$ to $10 \mathrm{~m}$ $(18000 \mathrm{~kg})$, from $1.662 \mathrm{~mm}$ to tending to zero, and then slowly increase.

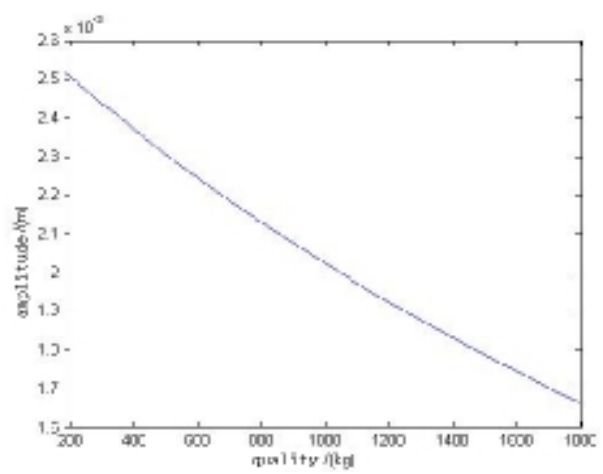

Fig.6 function relation curve of quality $(0.1 \mathrm{~m}-\mathrm{m})$

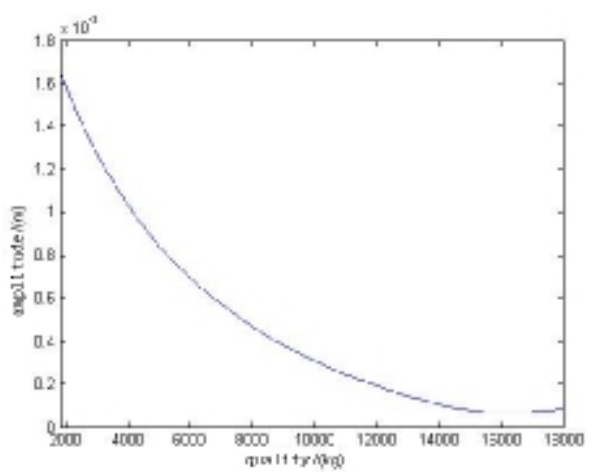

Fig.7 function relation curve of quality ( $\mathrm{m}-10 \mathrm{~m}$ ) about amplitude

Figure 8 , the amplitude increa- se sharply with the increase of $\mathrm{w}$, amplitude is equal to maximum $9.6 \mathrm{~mm}$ when the frequency is $18 \mathrm{r} / \mathrm{s}$.Amplitude sharply reduce with the increase of frequency, reach a minimum value, then the curve increases sharply, amplitude is equal to maximum $105.9 \mathrm{r} / \mathrm{s}$ when frequency is $2.32 \mathrm{~mm}$.

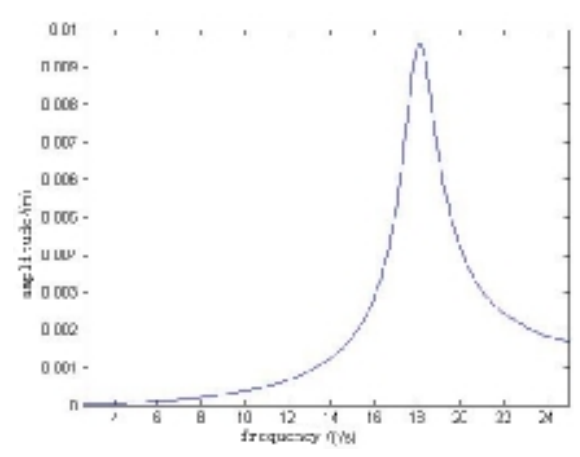

Fig.8 function relation curve of frequency $(0.1 w-w)$.

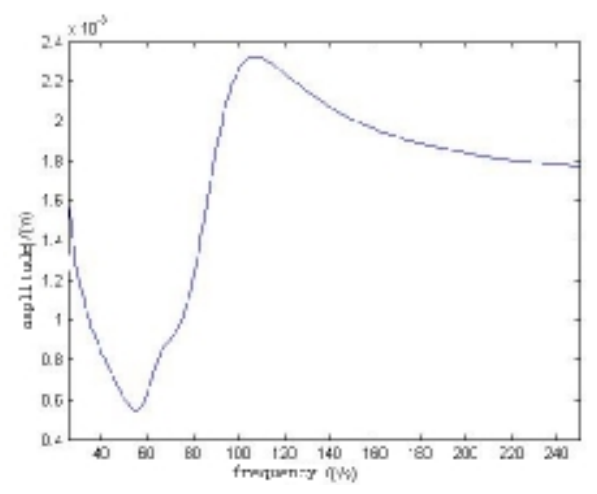

Fig.9 function relation curve of frequency (w-10w)about amplitude

\section{Conclusion}

DuringVibration roller compaction, when Soil quality is $200 \mathrm{~kg}$, the compaction effect is best; to the natural frequency of soil, wheel vibration amplitude is the largest, the compaction effect is best.

\section{Reference}

[1] Z.H.Zhang, The intelligent vibratory roller and technical status ,J Engineering machinery.3(2005) 5-8. (in Chinese) 
[2] D.Han, X.M.Huang, Y.Gao, Different parameters on the vibration road roller compaction effect analysis of soil base, J Highway traffic science and technology.8(2009) 1-5. (in Chinese)

[3] F.Gao, N.Wang, The influence of vibratory roller parameters on the compaction quality, J Construction machinery technology and management. 4(2015) 64-67. (in Chinese)

[4] J.F.Ren,Z.J.Chen, Vibration compaction system dynamic model and analysis, J Construction machinery.7(2005) 70-73. (in Chinese)

[5] S.C.Qin,Y.S.Cheng, Z.Li, Analysis on the coupled system of vibratory roller vibration wheel and soil, J Journal of tongji university,9(2001) 1026-1031. (in Chinese) 